

Open Access : : ISSN 1847-9286

www.jESE-online.org

Original scientific paper

\title{
Characterization of graphite-epoxy composite electrodes for free electrochemical detection of adenine and guanine in DNA
}

\author{
Leodanis Correa Fajardo, Abel Ibrahim Balbin Tamayo ${ }^{\varpi}$ and Ana Margarita \\ Esteva Guas
}

Department of Analytical Chemistry, Faculty of Chemistry, University of Havana, Zapata s/n between $G$ and Carlitos Aguirre, Vedado, Plaza de la Revolución, CP 10400. Havana, Cuba

Corresponding author: $\mathbb{i b r a h i m} @ f q . u h . c u$

Received: May 18, 2021; Accepted: September 19, 2021; Published: October 1, 2021

\begin{abstract}
Graphite-epoxy composites (GECS) are alternative construction materials for electrochemical sensors. For these materials, the electron transfer rate constant of some redox reaction depends additionally on the stoichiometric relationship between the insulating and conducting phases of the composite. In this work, the influence of different ratios of araldite/hardener/graphite on the electrochemical properties of GEC electrodes is evaluated for the simultaneous determination of adenine and guanine in the single chain DNA, using the square wave voltammetry technique. Six GEC electrodes were prepared with different ratios of components, and electrochemically characterized by cyclic voltammetry in the presence of ferri/ferrocyanide redox couple as a redox probe. GEC electrodes that showed the best electrochemical responses of redox probe were characterized by thermogravimetric analysis (TGA) and used for the simultaneous determination of free adenine and guanine in a solution, and DNA oligonucleotides. The best results were obtained for GEC electrodes containing twice higher volume of araldite resin with respect to the hardener. TGA analysis revealed presence of $15-26 \%$ of resin for these GEC electrodes. The obtained results revealed potential application of these GEC electrodes as DNA sensors based on the oxidation signal of guanine.
\end{abstract}

\section{Keywords}

electrochemical sensors; DNA oligonucleotides; graphite-polymer; thermogravimetric analysis.

\section{Introduction}

In recent years, the interest of scientific community in the development of electrochemical sensors as an alternative to DNA analysis, has been increased. These devices constitute useful tools in obtaining reliable genetic information in an economical way and real time. Due to advantages such as low cost, obtaining of sensitive signals, easy-interpretation, short response times, capability 
of working with small volumes, there is also a possibility of their integration into portable devices to carry out measurements in situ [1].

In this aspect, the development of carbon composite electrodes with polymeric matrices has led to a significant progress in electroanalytical chemistry. Advantages of polymer composite electrodes include the possibility of being easily modified, what improves their electrochemical properties, enhances their sensitivity and selectivity, and even converts them into specific materials $[1,2]$. These electrodes can be manufactured into different shapes and sizes, allowing easy adaptation to a wide variety of electronic configurations and application in different media. Furthermore, they exhibit a surface that can be renewed with simple polishing without involving the loss of modifiers [3]. Compared to pure conducting materials, polymer composites show better signal-to-noise ratio, since they behave like a microelectrode array, which generally contributes to lower detection limits $[4,5]$. Compared to typical voltammetric sensors, polymer composite electrodes have a stable electrochemical response, lower ohmic resistance, and longer functional life [6,7].

There is a number of literature reports on the potential application of graphite-epoxy composite electrodes in the analysis of nitrogenous bases in DNA. These electrodes showed higher sensitivity compared to glassy carbon electrodes and other composite materials $[1,8]$. The electrical properties of graphite-epoxy composite materials such as conductivity depend on the nature of each component, on the insulator/conductor proportions, and their distributions in the matrix of the material [9]. The electrical conductivity of these composites is determined by the connection of the conductive particles within the polymer matrix. Therefore, the relative amounts of each component must be evaluated to achieve the optimal relationship [1,5].

Until now, the investigations of epoxy-graphite composite electrodes have been focused mainly on their application as electrochemical sensors, leaving aside a study of their electrochemical properties. In some cases the influence of the percentage variation of graphite [10] or modifiers such as benzoic acid, stearic acid and graphene oxide [11-13], have been reported in describing electrochemical responses of graphite-epoxy composite electrodes.

In the study of electrochemical properties of composite electrodes, one of the most widely used characterization techniques is cyclic voltammetry (CV) technique that allows an investigation of the redox behavior of an analyte at the electrode surface in a wide range of potentials. The information on the electrode processes, which is obtained in these cases is qualitative, and allows obtaining of characteristic parameters such as potential values of oxidation and reduction, and corresponding peak currents intensities. In addition, some conclusions can be derived about kinetic aspects of electron transfer at the electrode surface, and interfacial aspects such as adsorption of electroactive species on the electrode surface [14]. Among other physicochemical characterization techniques, electrochemical impedance spectroscopy (EIS) $[15,16]$, scanning electron microscopy (SEM) $[17,18]$, differential scanning calorimetry (DSC) [19], thermogravimetric techniques (TG or DTG)[20,21], and spectroscopic techniques such as Raman spectroscopy [22] were applied.

The main aim of the present article is to evaluate the influence of araldite/hardener/graphite ratios on electrochemical properties of graphite-epoxy composite electrodes, applied for the simultaneous determination of oxidation signals of adenine and guanine of a single DNA strand.

\section{Experimental}

\section{Reagents}

All reagents used were of analytical quality, while deionized water with a conductivity of $1.26 \mu \mathrm{S} \mathrm{cm}^{-1}$ was used. For the construction of electrodes, pure quality benzyl alcohol (Uni-Chem) 
was used. Araldite from Beschleuniger DY 964 Serva Feinbiochemica, Gmbh, HR hardener from CIBA-GEIGY polymers, Duxford, and fine graphite powder with a particle size of $50 \mu \mathrm{m}$ from Merk (Germany) were supplied. The redox pair $\left[\mathrm{Fe}(\mathrm{CN})_{6}\right]^{3-/ 4-}$ of concentration $0.02 \mathrm{~mol} \mathrm{~L}^{-1}$ was prepared using potassium hexacyanoferrate(II) trihydrate, and potassium hexacyanoferrate(III) (Merk, Germany) in equimolar amounts in PBS buffer pH 6.9 from Sigma Aldrich. Sodium hydrogen phosphate (99\%) and sodium dihydrogen phosphate dihydrate (99\%) from Merk (Germany) were used for the preparation of phosphate buffer (PB), $\mathrm{pH} 7$ (supporting electrolyte) at $0.02 \mathrm{~mol} \mathrm{~L}^{-1}$. Sodium hydroxide (pure for analysis $>99 \%$ ) was used. The adenine and guanine used were SIGMA grade with a minimum purity of $99 \%$.

Adenine solutions of concentrations between 10-60 $\mu \mathrm{mol} \mathrm{L}^{-1}$ were prepared using PB, pH 7 . Guanine was initially dissolved in sodium hydroxide at $0.01 \mathrm{~mol} \mathrm{~L}^{-1}$ and subsequently, solutions of

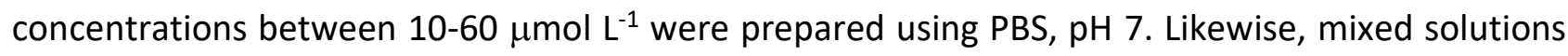
of adenine and guanine were prepared.

The single chain DNA (ssDNA) was the ST 36AR oligonucleotide, $100 \mu \mathrm{mol} \mathrm{L}^{-1}$ from Eurofins MWG Operon Corp. Canada, with the sequence 5'-TGACTCGTTGTCGATACCGACAGC-3', which was acquired from the Center for Protein Studies, Faculty of Biology, University of Havana.

\section{Equipment}

The voltammetric method was developed using a PalmSens potentiostat attached to a computer, managed by the PSTrace Software version 5.2, and operating in cyclic voltammetry and square wave voltammetry modes for voltammetric analyses. A three-electrode system was used, with graphiteepoxy composite working electrode(s), an auxiliary platinum electrode, and the reference $\mathrm{Ag} / \mathrm{AgCl}$ $\left(\mathrm{KCl}, 3 \mathrm{~mol} \mathrm{~L}^{-1}\right)$ electrode, from Basic Analytical Systems (BAS). Thermogravimetric analysis (TGA) was performed on a NETZSCH model 449 F3 Jupiter thermal analyzer. Deionized water was obtained from the water purifier, Milli-Q, HPW Pure Water System, Heal-Force (China).

\section{Preparation of graphite-epoxy composite electrodes}

For the construction of graphite-epoxy composite (GEC) electrodes, mixtures with the same mass of the conductive phase (graphite) and different ratios between the polymer (araldite) and HR hardener (diamine) in the insulating phase were prepared. Replicas of six types of composites (GECI to GEC-VI) electrodes with different ratios of araldite/hardener/benzyl alcohol were constructed (Table 1). Benzyl alcohol was used to reduce the viscosity of the composite mixture. The theoretical percentages of graphite in the electrodes are also shown in Table 1.

Table 1. Epoxy resin/hardener/benzyl alcohol volume ratio and theoretical content of graphite in GEC-I to GEC-VI electrodes

\begin{tabular}{ccccc}
\hline \multirow{2}{*}{ Electrode } & \multicolumn{3}{c}{ Volume, $\mathrm{mL}$} & \multirow{2}{*}{ Graphite content, \% } \\
\cline { 2 - 5 } & Epoxy resin & Hardener & Benzyl alcohol & 59.6 \\
\hline GEC-I & 5.8 & 1 & 2 & 67.4 \\
\hline GEC-II & 3.8 & 1 & 2 & 77.4 \\
\hline GEC-III & 2.0 & 1 & 2 & 55.8 \\
\hline GEC-IV & 5.4 & 2 & 1 & 62.5 \\
\hline GEC-V & 3.6 & 2 & 1 & 71.0 \\
\hline GEC-VI & 2.0 & 2 & 1 & \\
\hline
\end{tabular}

The electrodes were constructed by introducing the composite mixture obtained in each case into glass capillaries of approximately $1 \mathrm{~mm}$ in diameter. For electronic contact, a copper wire was inserted. The prepared electrodes were heated for 48 hours at $40{ }^{\circ} \mathrm{C}$ in an oven to dry. Later, the electrode surface was polished to perform the corresponding tests $[13,22]$. 


\section{Experimental procedure}

For the electrochemical characterization of the constructed GEC electrodes, cyclic voltammetry (CV) technique was applied. Using a three-electrode system, the electrochemical response of the redox system $\left[\mathrm{Fe}(\mathrm{CN})_{6}\right]^{3-/ 4-}$ at prepared composite electrodes was evaluated. The analytical signal was obtained by applying a triangular potential sweep between -700 and $700 \mathrm{mV}$, with an increase of $4 \mathrm{mV}$, while scan rate $(v)$ was varied from $20-100 \mathrm{mV} \mathrm{s}^{-1}$.

Square wave voltammetry (SWV) technique was used to determine free purines. The electrochemical signal was obtained by applying a potential sweep between $500 \mathrm{mV}$ and $1600 \mathrm{mV}$, at the frequency of $10 \mathrm{~Hz}$, and a pulse width of $10 \mathrm{mV}$. To carry out this analysis, the electrodes were previously mechanically polished $[13,22]$, electrochemically cleaned with several cycles of cyclic voltammetry (from 500 to $1200 \mathrm{mV}$, at $50 \mathrm{mV} \mathrm{s}^{-1}$ ) in $0.1 \mathrm{~mol} \mathrm{~L}^{-1}$ sodium hydroxide solution, and finally washed thoroughly with distilled water.

For the electrochemical analysis of DNA, GEC electrodes were mechanically [13,22] and electrochemically cleaned as explained above. To detect the signs of oxidation of adenine and guanine in the oligonucleotide, the latter was heated in a water bath to the boiling temperature $\left(T=78{ }^{\circ} \mathrm{C}\right)$ in order to achieve elongation of DNA oligonucleotide chains [23]. Subsequently it was deposited on the electrode by means of wet adsorption, and a square wave voltammetry was performed in $0.02 \mathrm{~mol} \mathrm{~L}^{-1} \mathrm{~PB}, \mathrm{pH} 7$ under the aforementioned conditions.

For the thermal analysis of graphite-epoxy composites by means of thermogravimetric analysis (TGA), the thermograms were obtained in a temperature range of $25-1000{ }^{\circ} \mathrm{C}$, at a heating rate of $10^{\circ} \mathrm{C} \mathrm{min}^{-1}$ and Ar flow of $20 \mathrm{~mL} \mathrm{~min}-1$.

\section{Results and discussion}

Electrochemical characterization of GEC electrodes by $\left[\mathrm{Fe}(\mathrm{CN})_{6}\right]^{3-/ 4-}$ redox system

The reversibility of the redox system $\left[\mathrm{Fe}(\mathrm{CN})_{6}\right]^{3-/ 4-}$ was tested on the prepared GEC electrodes by cyclic voltammetry (CV) technique. From CVs obtained, the influence of the potential scanning rate $(v)$ on the current intensity values and the potential difference between redox peaks $(\Delta E)$ were evaluated. Figure 1 shows cyclic voltammograms (CVs) of GEC-I to GEC-VI electrodes, recorded at various potential scan rates.

CVs of composite electrodes shown in Fig. 1 are characteristic for the redox system $\left[\mathrm{Fe}(\mathrm{CN})_{6}\right]^{3-/ 4-}$. At negative potentials a peak with negative current (cathodic peak), corresponding to the reduction of $\left[\mathrm{Fe}(\mathrm{CN})_{6}\right]^{3-}$ (ferricyanide) ions is observed and at higher potentials the anodic peak with positive current intensity, corresponding to the oxidation of $\left[\mathrm{Fe}(\mathrm{CN})_{6}\right]^{4-}$ (ferrocyanide) is presented [24]. In all cases, an increase in the peak current intensity and slight increase in the potential difference between two current peaks can be observed by increasing the scan rate [14,24-26].

Figure 2 shows the variation of potential difference between redox peaks $(\Delta E)$ with the scan rate for each GEC electrode.

For all GEC electrodes, $\Delta E$ values increase more or less with the sweep rate and are generally higher than the values already reported in the literature for a reversible system [14,24-26]. This can be influenced by the variation in the composition of the graphite-epoxy composite and its interaction with possible molecular rearrangements during the electrode processes on the electrode surface, without bond breakage and mass transfer phenomena occurring $[14,26]$.

For GEC-I and GEC-IV electrodes it is observed that $\Delta E$ values are the highest, and also show greater dependence on the potential sweep rate. This may be due to the fact that the applied 
potential does not create necessary concentrations, according to the Nernst equation at the electrode surface, and therefore an overpotential is generated.
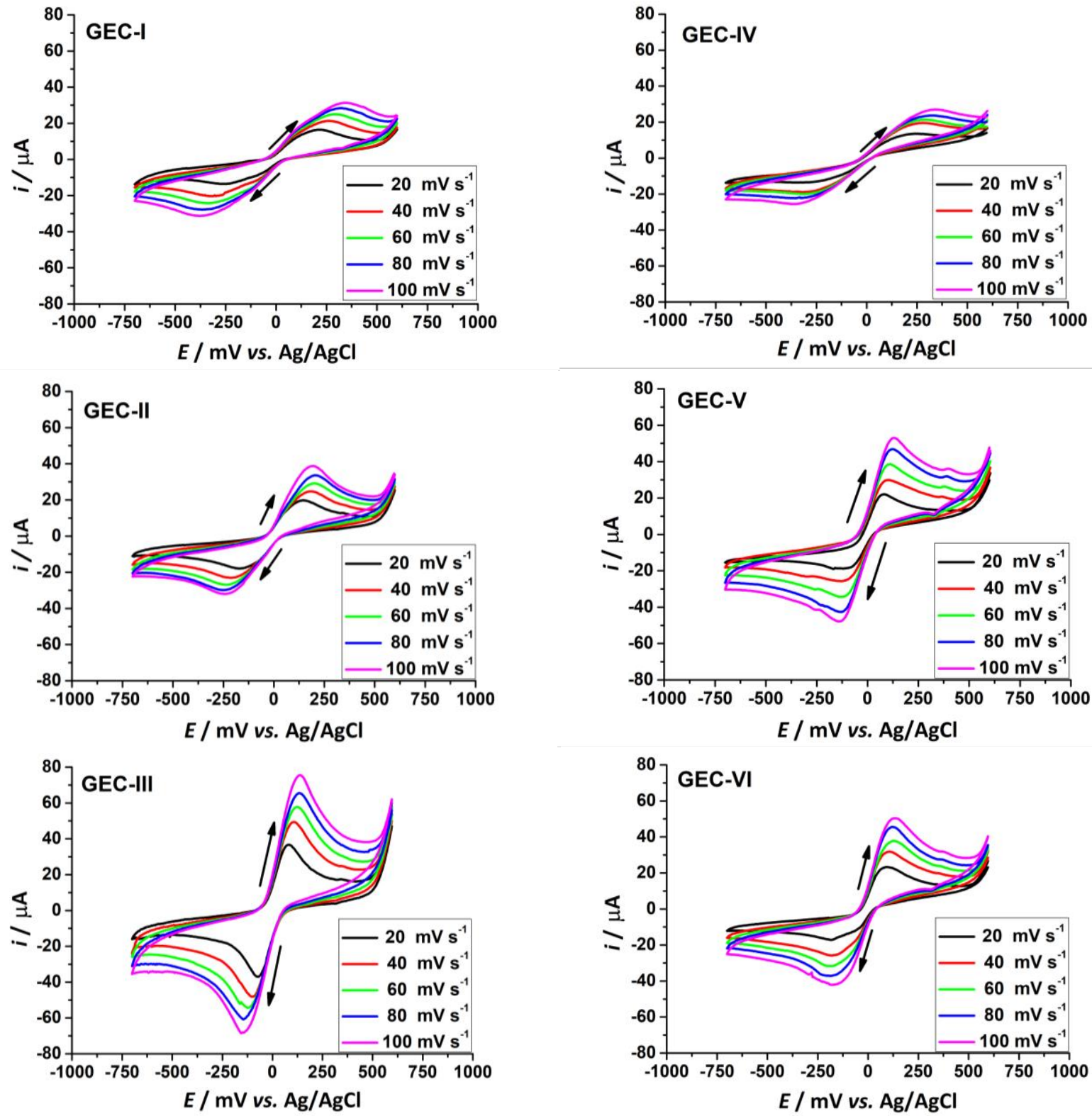

Figure 1. CVs of GEC-I to GEC-VI electrodes in $0.02 \mathrm{~mol} \mathrm{~L}^{-1}\left[\mathrm{Fe}(\mathrm{CN})_{6}\right]^{3-/ 4}$ for $0.02 \mathrm{~mol} \mathrm{~L}^{-1} \mathrm{PBS}$ pH 6.9, at scan rates between $20-100 \mathrm{mV} \mathrm{s}^{-1}$

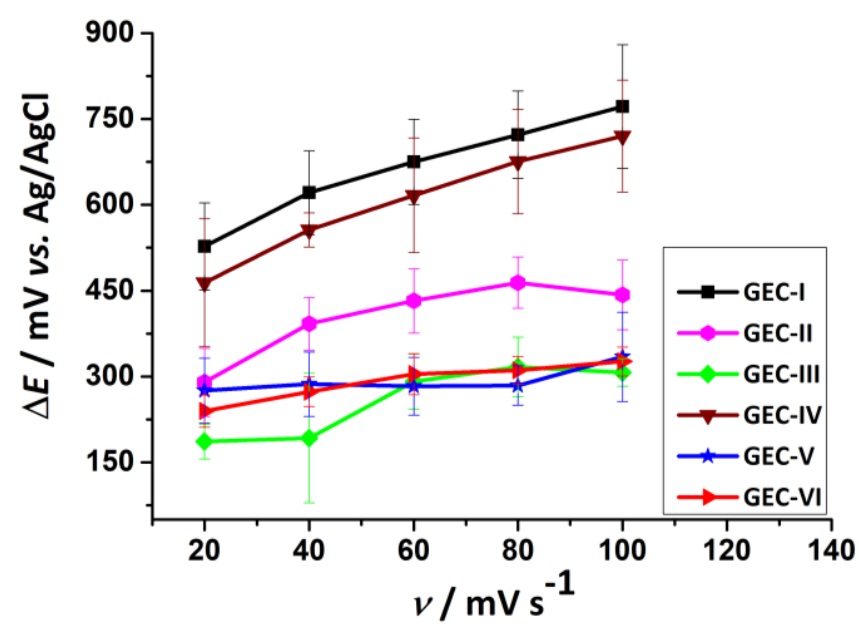

Figure 2. Variation of $\triangle \mathrm{E}$ with potential scan rate $(v)$ for GEC-I to GEC-VI electrodes 
In this aspect, the energy required to carry out the electrode processes is much higher than for other GEC electrodes. This may be associated with an increase in the resistance of the composite, as a result of a higher content of the insulating phase (lower content of graphite) compared to other GEC electrodes (Table 1). In contrast, GEC-III, GEC-V, GEC-VI electrodes show lower $\Delta E$ values that are almost independent on the potential sweep rate. In this case, the behavior of the electrodes is characteristic for the systems that are closer to reversibility, indicating that oxidation-reduction process on the electrode surface occurs with less overpotential and energy cost [14]. GEC-II electrode showed an intermediate behavior, indicating less electrochemically active surface in this case.

These results can be associated with three levels of graphite percentage (cf. Table 1). The most dependent on the potential sweep rate are GEC-I and GEC IV electrodes, with percentages of graphite between 55-60\%. The electrodes which present the behavior closer to reversible are GECIII and GEC-VI electrodes, with percentages of graphite between 71-77\%. Among the remaining GEC-II and GEC-V electrodes with percentages of graphite around $65 \%$ [10] only GC-II electrode showed an intermediate behavior, while GEC-V electrode, despite similar percentage of graphite, showed much better electrochemical response of $\left[\mathrm{Fe}(\mathrm{CN})_{6}\right]^{3-/ 4-}$ redox pair. This may be associated with the influence of the araldite/hardener ratio on the curing of the compound [27] on its electrochemical properties. Therefore, it can be assumed that when the araldite/hardener ratio is about 2:1 (Table 1), better electrochemical properties of electrodes are achieved, which can be independent of the percentage of graphite in a narrow range. Among here manufactured electrodes this araldite/hardener ratio was accomplished for GEC-III and GEC-V electrodes.

\section{Kinetic parameters of the redox system $\left[\mathrm{Fe}(\mathrm{CN})_{6}\right]^{3-/ 4-}$ at GEC electrodes}

To analyze the influence of the scan rate on the peak current intensity, it was taken into account that for a quasi-reversible processes controlled by diffusion, the peak current is defined according to the Randles-Ševčik equation $[25,28]$, which is at $25^{\circ} \mathrm{C}$ defined as:

$$
i_{\mathrm{p}}=2.99 \times 10^{5} \alpha^{1 / 2} n^{3 / 2} A D^{1 / 2} C v^{1 / 2}
$$

In equation (1), $i_{\mathrm{p}}$ is peak current intensity in A, $\alpha$ is electron transfer coefficient, $n$ is the number of electrons exchanged, $A$ is area of the electrode in $\mathrm{cm}^{2}, D$ is diffusion coefficient of redox species in $\mathrm{cm}^{2} \mathrm{~s}^{-1}, C$ is concentration of this species within the solution in mol cm $\mathrm{cm}^{-3}$ and $v$ is the scan rate in $\mathrm{V} \mathrm{s}^{-1}$.

Taking this equation into account, for diffusion-controlled processes, the peak current intensity would be proportional to the square root of the sweep rate. Figure 3 shows the linear relationship of the anodic peak current $\left(i_{p}\right)$ as a function of the square root of the sweep rate for each GEC electrode. In all cases, an increase in $i_{p}$ was observed with increasing potential sweep rate. In addition, since the intensity of the current is proportional to the flow towards the surface of the electrodes, it can be argued that this magnitude is small at low sweep rates and increases when the potential is swept at higher speeds [2].

From Figure 3 it is observed that for all GEC electrodes, the anodic peak current values were well adjusted to straight lines with correlation coefficients greater than 0.98 . These results indicate that the electrode processes that occur on the surface of the electrodes are controlled by diffusion within the experimental error, and the time scale of the experiment. Additionally, the constant term of the Randles-Ševčik equation [(2.99·10 $\left.) \alpha^{1 / 2} n^{3 / 2} A D^{1 / 2} C\right]$ was evaluated, as a slope of the linear regression between $i_{p} v s . v^{1 / 2}$, that is a measure of sensitivity of the electrode. Parameters of linear regression for GEC-I to CEC-VI electrodes are summarized in Table 2. 


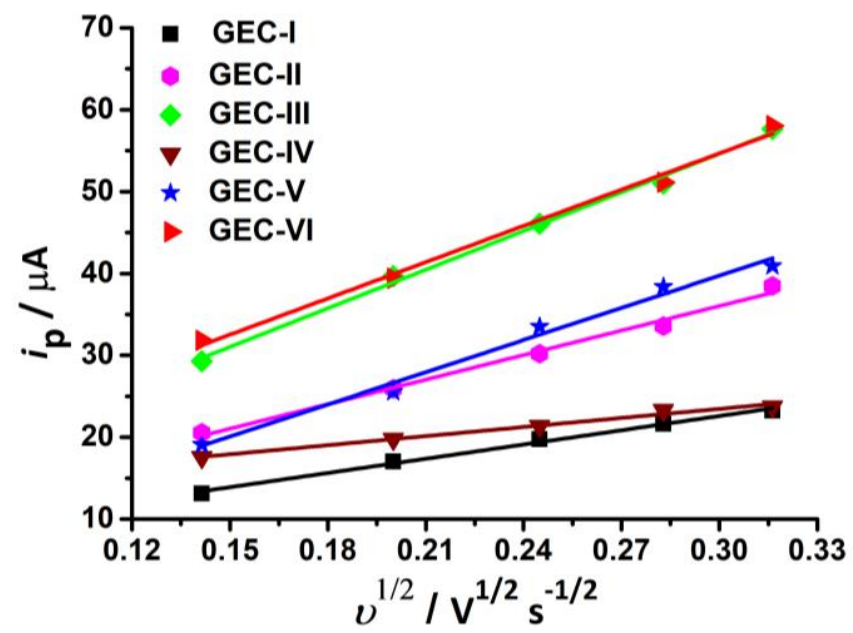

Figure 3. Linear regression of anodic $\mathrm{i}_{p}$ as a function of $v^{1 / 2}$ for GEC-I to GEC-VI electrodes

Table 2. Parameters of linear regression of $\mathrm{i}_{\mathrm{p}} \mathrm{vs}$. $\mathrm{v}^{1 / 2}$ for GEC-I to GEC-VI electrodes.

\begin{tabular}{ccccccc}
\hline Electrode & Slope & $R^{2}$ & & Electrode & Slope & $R^{2}$ \\
\hline GEC-I & $58 \pm 2$ & 0.993 & & GEC-IV & $37 \pm 3$ & 0.982 \\
\hline GEC-II & $99 \pm 5$ & 0.989 & & GEC-V & $131 \pm 8$ & 0.984 \\
\hline GEC-III & $157 \pm 6$ & 0.995 & & GEC-VI & $148 \pm 8$ & 0.991 \\
\hline
\end{tabular}

The results shown in Table 2 reveal greater slope values for GEC-III and GEC-VI electrodes, and to a lesser extent for GEC-V electrode, which is indicative of greater sensitivity of these electrodes against the redox system $\left[\mathrm{Fe}(\mathrm{CN})_{6}\right]^{3-/ 4-}$.

To identify the possible existence of coupled chemical reaction(s) during the electrode processes, the ratio of anodic $\left(i_{\mathrm{pa}}\right)$ and cathodic $\left(i_{\mathrm{pc}}\right)$ peak current intensities for each type of GEC electrode was analyzed. For a reversible system without kinetic complications, the peak currents $i_{\mathrm{pa}}$ and $i_{\mathrm{pc}}$ are equal, i.e. the ratio $i_{\mathrm{pa}} / i_{\mathrm{pc}} \approx 1$, and independent of the potential sweep rate and diffusion coefficients $[25,26]$. Figure 4 shows that for all analyzed GEC electrodes, the ratio between peak currents remains practically constant with the increase of potential sweep rate. Additionally, for all electrodes it can be seen that at any $v$, the peak current ratio takes value greater than unity, which may indicate possible coupled chemical reaction carried out during the charge transfer processes [26].

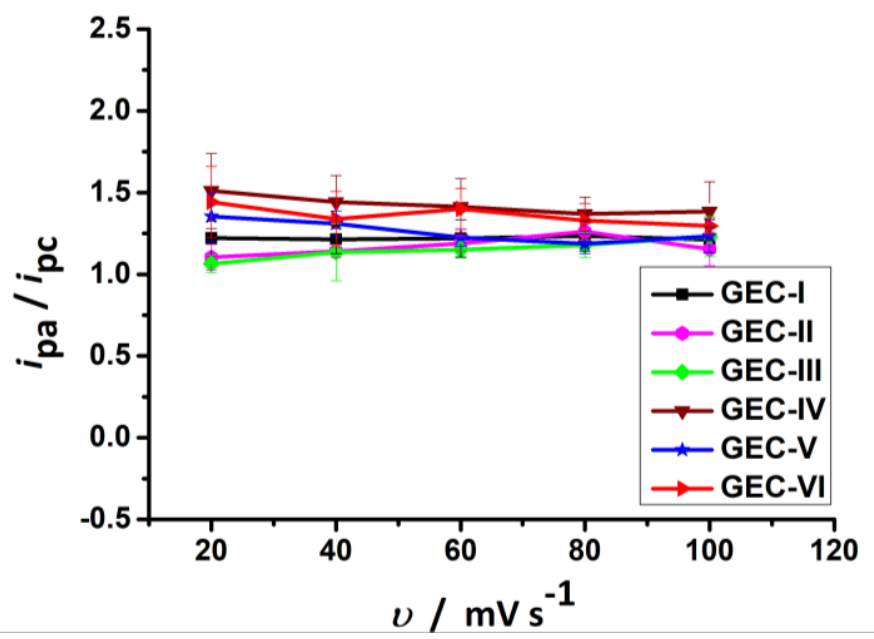

Figure 4. Peak current ratio ( $\left.\mathrm{i}_{p a} / \mathrm{i}_{p c}\right)$ for GEC-I to GEC-VI electrodes as a function of the potential scan rate $v$

Heterogeneous electron transfer rate constants $\left(k^{\circ}\right)$ were determined for each GEC electrode. From $\Delta E$ values obtained in CV profiles, the values of the dimensionless kinetic parameter $\Psi$ were 
estimated, taking into account the relationship between $\Psi$ and $\Delta E_{\mathrm{p}}$ proposed by Nicholson in 1965 . $\mathrm{k}^{\mathrm{o}}$ values were determined according to the following equation [29].

$$
k_{\mathrm{o}}=\Psi\left(\pi D_{\mathrm{o}} \frac{n F v}{R T}\right)^{1 / 2}
$$

where $D_{o}$ is diffusion coefficient of the oxidized species $\left(\mathrm{cm}^{2} \mathrm{~s}^{-1}\right), n$ is the number of electrons transferred during the redox reaction, $v$ is potential scanning rate $\left(\mathrm{V} \mathrm{s}^{-1}\right), F$ is Faraday constant $\left(96485 \mathrm{C} \mathrm{mol}^{-1}\right), R$ is ideal gas constant $\left(8.314 \mathrm{~J} \mathrm{~mol}^{-1} \mathrm{~K}^{-1}\right)$, and $T$ is absolute temperature (298.15 K).

During this analysis it was observed that GEC-I, GEC-II, and GEC-IV electrodes showed a high resistance to electron transfer, since for these cases, values of the constant $k^{\circ}$ are below the limit that can be determined by the Nicholson method $\left(<4.6 \times 10^{-3} \mathrm{~cm} \mathrm{~s}^{-1}\right)$ [14]. On the other hand, the electrochemical reactions that occur on the surface of the remaining electrodes are carried out with appreciable rates, as shown by their $k^{0}$ values (GEC-III: $(1.2 \pm 0.7) \times 10^{-2}$; GEC-V: $(1.0 \pm 0.4) \times 10^{-2}$; GEC-VI: $(6.6 \pm$ $\left.\pm 1.7) \times 10^{-3} \mathrm{~cm} \mathrm{~s}^{-1}\right)$. For these latter electrodes, it could be observed that the values of the heterogeneous electron transfer constant are within the range of the quasi-reversible processes, considering the limiting scanning speeds $\left(3 \times 10^{-3} v^{1 / 2} \geq k^{0} \geq 2 \times 10^{-7} v^{1 / 2}\right)[26]$.

GEC-III, GEC-V and GEC-VI electrodes showed the highest $k^{\circ}$ values, indicating that the kinetics of the electron transfer that occurs on the electrode surfaces during redox process is faster, and typical for a quasi-reversible system [24]. These results correspond to the higher percentage of graphite (conductive phase) of these electrodes with respect to the rest. In spite of somewhat lower graphite content, however, GEC-V electrode showed $k^{\circ}$ value very similar to that of GEC-III electrode, which may be associated with the influence of the araldite/hardener ratio on the electrochemical properties of the electrode.

Individual and simultaneous determination of adenine and guanine at GEC electrodes

Square wave voltammograms recorded for GEC-III, GEC-V and GEC-VI electrodes in adenine containing PB pH 7 solution, are shown in Figure 5. For each GEC electrode, well defined oxidation peak of high symmetry is observed at $950 \mathrm{mV}$.

For GEC-III and GEC-V electrodes, the increase of adenine concentration caused proportional increase in the current intensity of the oxidation peak for this molecule. The linear regression between the oxidation peak current and adenine concentration was significant for these two electrodes, with high values of correlation coefficients (GEC-III: $R^{2}=0.993$, GEC-V: $R^{2}=0.994$ ). In contrast, GEC-VI electrode is obviously less sensitive to changes in adenine concentration, since the linear regression between the current intensity of the oxidation peak and adenine concentration was not significant $\left(R^{2}=0.927\right)$. This result for GEC-VI electrode can be influenced by the surface passivation that causes reduction of electrochemical activity of the surface, thus establish the sensitivity of the electrode to change in adenine concentration $[30,31]$.

GEC-III and GEC-V electrodes were used for the simultaneous determination of free adenine and guanine mixed in PB solution. Figure 6 shows SWVs for each type of GEC electrode, where it is observed that in both cases, the increase in concentration caused proportional increase in the intensity of oxidation peaks for both molecules.

It can be seen from Figure 6 that adenine and guanine generate highly defined and symmetrical oxidation peaks, separated by $\Delta E$ of around $270 \mathrm{mV}$. Almost no difference in the oxidation potential values for guanine and adenine between two GEC electrodes is observed. 



Figure 5. SWVs of different concentrations of adenine in $0.02 \mathrm{~mol}^{-1} P B(p H$ 7) for GEC-III, GEC-V and GEC-VI electrodes
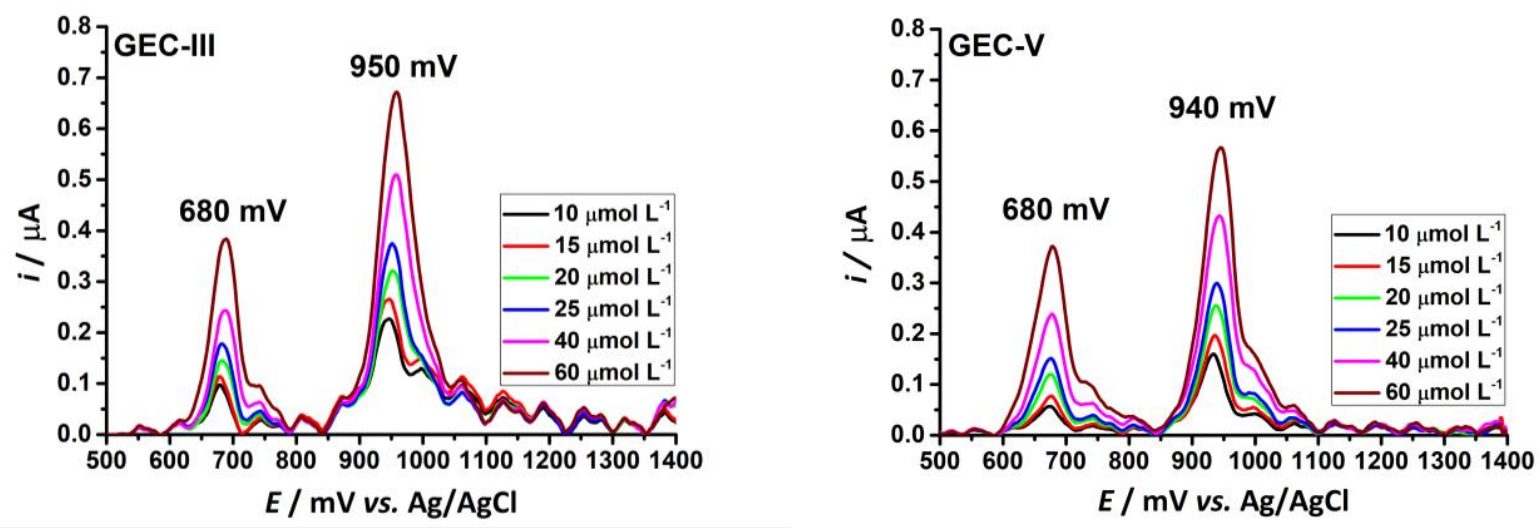

Figure 6. SWVs of different concentrations of mixed adenine and guanine solutions in $0.02 \mathrm{~mol}^{-1} P B(\mathrm{pH}$ 7) for GEC-III and GEC-V electrodes

Compared to other electrodes already used for the development of DNA sensors, the oxidation potentials of adenine (A) and guanine (G) at GEC-III and GEC-V electrodes are somewhat lower than previously reported. Thus, for glassy carbon electrodes modified with graphene and Nafion, $820 \mathrm{mV}$ for $\mathrm{G}$ and $1180 \mathrm{mV}$ for $\mathrm{A}$ were obtained by differential pulse voltammetry [32]. For graphene electrodes modified with platinum nanoparticles, $830 \mathrm{mV}$ for $\mathrm{G}$ and $1190 \mathrm{mV}$ for $\mathrm{A}$, were determined by linear scanning voltammetry [33]. For carbon composite electrodes and nanoparticles of graphene oxide modified with poly (L-cysteine), magnetite and DNA (ds-DNA/p(L-Cys)/Fe $\mathrm{O}_{4} \mathrm{NPs}$ $\mathrm{GO} / \mathrm{CPE}$ ), $830 \mathrm{mV}$ for $\mathrm{G}$ and $1120 \mathrm{mV}$ for A were determined by differential pulse voltammetry [34]. In benzoic acid modified graphite-epoxy composite electrodes, $620 \mathrm{mV}$ for $\mathrm{G}$ and $1260 \mathrm{mV}$ for adenine, were obtained by square wave voltammetry [22]. All these results suggest that the purine bases showed the best electrochemical response at here built graphite-epoxy electrodes. 
At GEC-III and GEC-V electrodes, guanine oxidizes at lower potential than adenine, which indicates that the electrochemical oxidation processes for this molecule occurs with a lower overpotential and with lower energy consumption, which is in the correspondence with previous reports [31,35].

Figure 7 represents the graphs of linear regressions between the values of current intensity of oxidation peaks and concentrations of adenine and guanine, respectively. For both GEC electrodes, the peak current values are adjusted adequately to straight lines for both adenine and guanine, giving high correlation coefficient values. Results of regression procedures for adenine and guanine are summarized in Table 3.
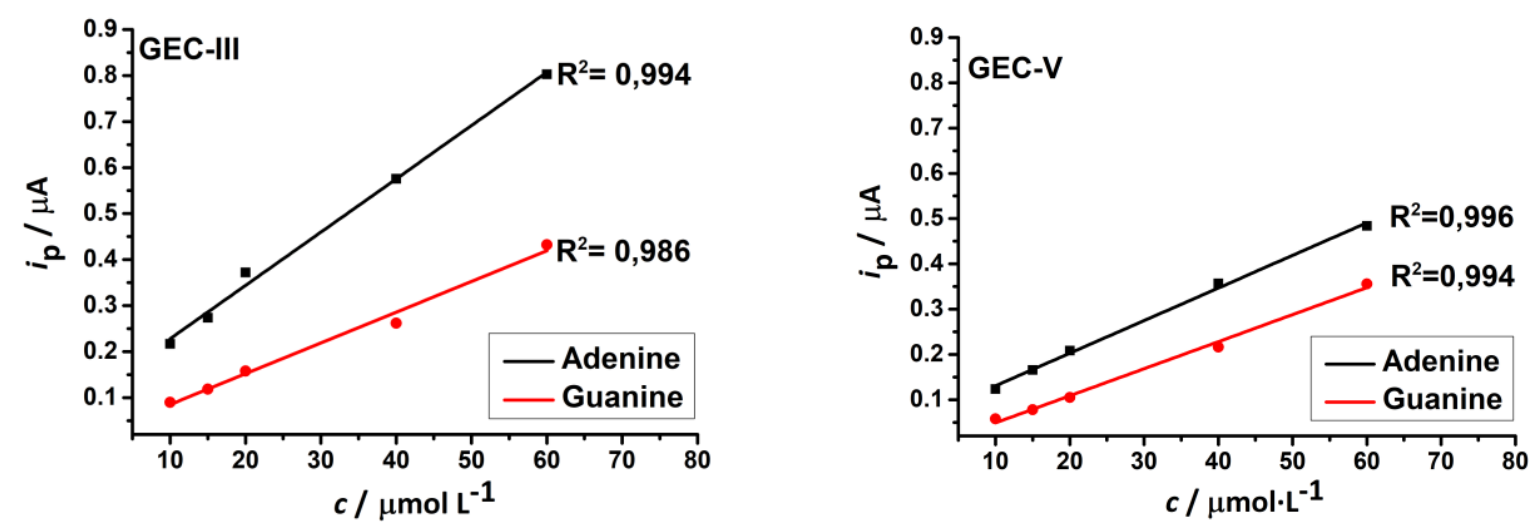

Figure 7. Linear regression between peak oxidation current and concentration of adenine and guanine for GEC-III and GEC-V electrodes

Table 3. Results of linear regression between $i_{p}$ and concentration of adenine and guanine at GEC-III and GEC-V electrodes

\begin{tabular}{cccccc}
\hline Electrodes & $\begin{array}{c}\text { Slope, } \\
\mathrm{A} \mathrm{L} \mathrm{mol}\end{array}$ & $\begin{array}{c}\text { Standard error, } \\
\mathrm{AL} \mathrm{mol}\end{array}$ & Intercept, A & Standard error, A & Equation \\
\hline GEC-III & 0.0116 & 0.0005 & $1.1 \times 10^{-7}$ & $2 \times 10^{-8}$ & $i_{\mathrm{p}}=0.0116 c+1.1 \times 10^{-7}$ \\
\hline GEC-V & 0.0072 & 0.0002 & $6.0 \times 10^{-8}$ & $7 \times 10^{-9}$ & $i_{\mathrm{p}}=0.0072 c+6.0 \times 10^{-8}$ \\
\hline \multicolumn{5}{c}{ Guanine } \\
\hline GEC-III & 0.0067 & 0.0004 & $2 \times 10^{-8}$ & $10^{-8}$ & $i_{\mathrm{p}}=0.0067 c+2 \times 10^{-8}$ \\
\hline GEC-V & 0.0060 & 0.0002 & $-1.1 \times 10^{-8}$ & $8 \times 10^{-9}$ & $i_{\mathrm{p}}=0.0060 c-1.1 \times 10^{-8}$ \\
\hline
\end{tabular}

From the results reported in Table 3, it appears that GEC-III electrode, having higher slope values is more sensitive to the determination of both molecules compared to GEC-V electrode. These results indicate that the electrochemical oxidation processes at GEC-III electrode surface is carried out with faster electron transfer kinetics, what corresponds to the determined heterogeneous electron transfer rate constant $\left(k^{\circ}\right)$ value. As expected, both electrodes are found more sensitive to adenine determination, since this molecule is more electrochemically active and exchanges larger number of electrons during oxidation processes [30,31].

Electro-oxidation of adenine and guanine in DNA oligonucleotide

Purine bases were determined in the single-stranded DNA sample (ST 36AR oligonucleotide), using GEC-III and GEC-V electrodes since they showed better-electrochemical responses of the redox system $\left[\mathrm{Fe}(\mathrm{CN})_{6}\right]^{3-/ 4-}$, and better results in the simple determination of adenine (Figure 5) and simultaneous determination of adenine and guanine (Figure 6). Figure 8 shows SWVs of singlestranded DNA in PB, pH 7.0 solution at GC-III and GCE-V electrodes. 


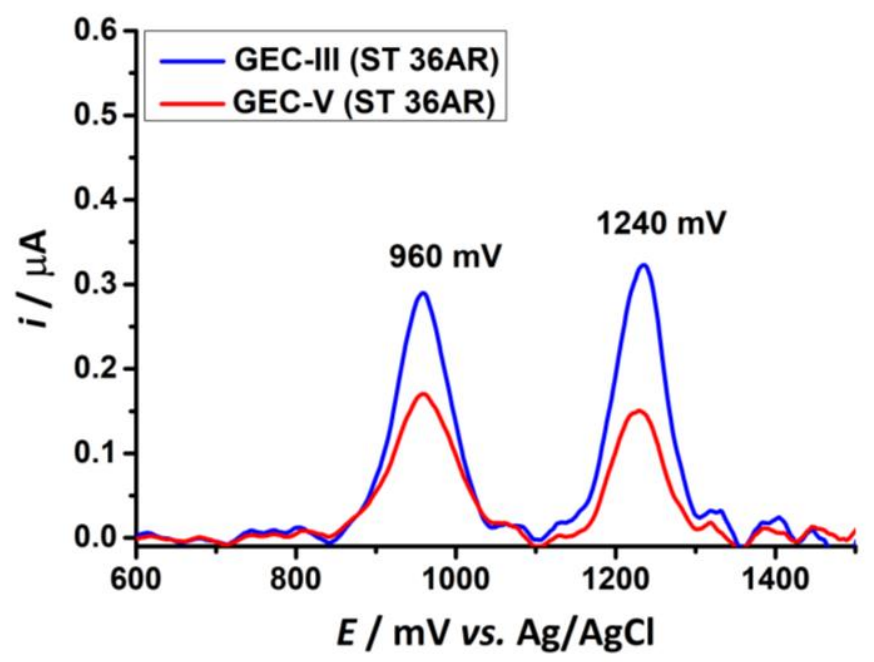

Figure 8. SWVs of $100 \mu \mathrm{mol} \mathrm{L}^{-1}$ single-stranded DNA solution (ST 36AR oligonucleotide) in $0.02 \mathrm{~mol} \mathrm{~L}^{-1} \mathrm{~PB}$ ( $\mathrm{pH}$ 7) for GEC-III and GEC-V electrodes

It can be seen in Figure 8 that for both GEC electrodes, the presence of ST 36AR oligonucleotide generates two very well defined and highly symmetrical oxidation signals, separated by $\Delta E$ of $280 \mathrm{mV}$. GEC-III electrode showed more intense oxidation peaks compared to GEC-V electrode, as a consequence of the greater sensitivity of GEC-III electrode in detecting both nitrogenous bases, as already shown in Figure 7 and Table 3. As can be seen, $\Delta E$ that separates two oxidation signals in the oligonucleotide is very similar to that obtained for free purines (approximately $270 \mathrm{mV}$ in Figure 6). This was used as a criterion to identify that the signal at $960 \mathrm{mV}$ is due to the oxidation of guanine, while the signal at $1240 \mathrm{mV}$ to adenine oxidation. Furthermore, in this potential range, the main oxidation signals are obtained to determine single DNA strands. [30,31].

As shown in Figure 9, the potentials at which the purine bases in the ST 36AR oligonucleotide are oxidized, are higher than oxidation potentials provided when these nitrogenous bases are in their free form [30,31].

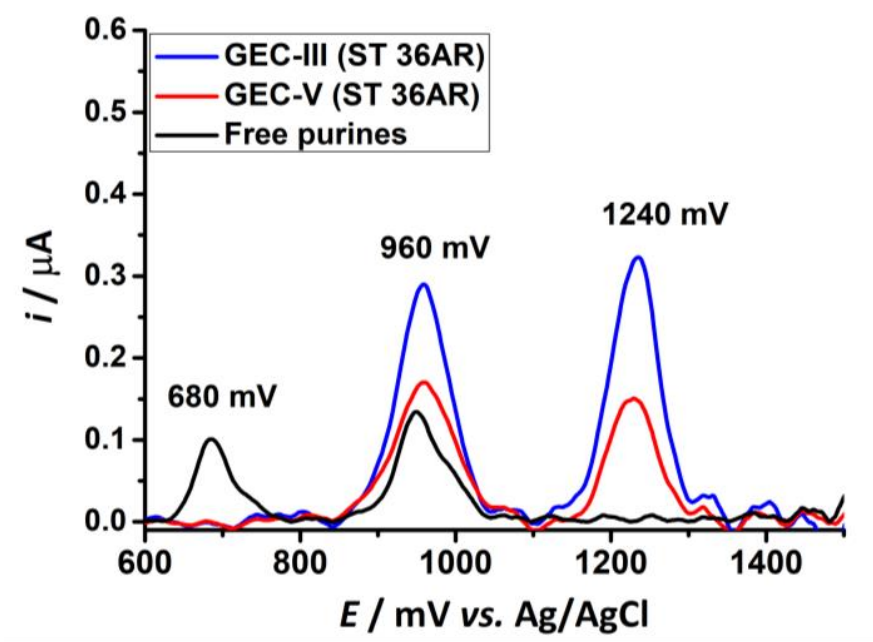

Figure 9. SWVs of $100 \mu \mathrm{mol} L^{-1}$ single-stranded DNA solution and $10 \mu \mathrm{mol} L^{-1}$ mixed solution of adenine and guanine in $0.02 \mathrm{~mol}^{-1} P B(p H$ 7) for GEC-III and GEC-V electrodes

The higher oxidation potentials of adenine and guanine in the oligonucleotide compared to the oxidation potentials of free purine bases is associated with the difficulty of oxidation of these nitrogenous bases when they are committed within a single DNA chain. This may be associated with steric impediments due to phosphate groups in the DNA chain and possible interactions that can occur 
between complementary bases in the DNA chain, causing it to fold and at the distance that separates the purine bases and the electroactive surface of the electrode [30,31]. All these molecular factors can cause an overpotential to be generated to achieve oxidation of the purine bases.

Thermogravimetric analysis (TGA) of GEC-III, GEC-V and GEC-VI electrodes

The electrodes that showed better electrochemical responses (GEC-III, GEC-V, GEC-VI) for ferri/ferrocyanide couple, were characterized by TGA. TGA was performed, in order to evaluate the composition and analyze the stoichiometry of the curing reaction between the epoxy resin and diamine (hardener). Figure 10 shows TG and DTG curves obtained.



Figure 10. Thermogravimetric analysis of GEC-III, GEC-V and GEC-VI electrodes

The thermograms obtained for three chosen GEC electrodes showed fairly similar behavior. Two losses of mass were generally detected, where the first loss of mass was identified between 100-270 ${ }^{\circ} \mathrm{C}$, corresponding to decomposition of the hardener that remained unreacted. The second loss of mass took place around $270-480{ }^{\circ} \mathrm{C}$, corresponding to thermal decomposition of the epoxy resin. The decomposition temperature intervals shown in this analysis correspond to those obtained evaluating the components separately, as is already reported in the literature $[36,37]$.

In compositions of three analyzed GEC electrodes, an excess of hardener was detected, as expected according to the stoichiometry of the reaction, because the amount of substance of the equivalent of the epoxy resin initially used for the construction of the electrodes, was greater than the amount of substance of the equivalent of the hardener.

From TGA results summarized in Table 4, it can be seen that GEC-III and GEC-VI electrodes show very similar composition. The experimental values obtained from the percentage of residue are close to the added graphite values. The difference can be associated to the residual carbon product of the decomposition of the excess hardener and the resin. The greater percentage of excess hardener detected for GEC-VI electrode can explain its low surface electrochemical activity in the simple determination of adenine. The lower sensitivity of GEC-V electrode in the determination of purines with respect to GEC-III electrode, may be associated with its higher content of insulating phase, which causes lower surface reactivity to the redox process of the nitrogenous bases of DNA. 
Table 4. Composition obtained from TGA data for GEC-III, GEC-V and GEC-VI electrodes

\begin{tabular}{|cccc|}
\hline \multirow{2}{*}{ Electrode } & \multicolumn{3}{c|}{ Content, wt.\% } \\
\cline { 2 - 4 } & Hardener & Resin & Residue \\
\hline GEC-III & 7.2 & 15.2 & 77.6 \\
\hline GEC-V & 6.2 & 26.1 & 67.7 \\
\hline GEC-VI & 8.1 & 13.7 & 78.2 \\
\hline
\end{tabular}

This analysis shows that percentages of resin (insulating phase) between $15-26 \%$ ensure adequate electrochemical response of the graphite-epoxy composite in the determination of nitrogenous bases in DNA.

\section{Conclusions}

Graphite epoxy- composite (GEC) electrodes with different epoxy resin/hardener/graphite ratios were prepared as sensors for adenine and guanine detection in DNA. The analysis of cyclic voltammetry experiments performed using the system $\left[\mathrm{Fe}(\mathrm{CN})_{6}\right]^{3-/ 4}$ as a redox probe showed a quasi-reversible behavior, i.e. the redox reaction controlled by diffusion, for all prepared GEC electrodes. More detailed kinetic analysis showed, however, that more reversible response of redox probe is indicated at GEC electrodes having twice higher volume of araldite resin with respect to the hardener.

The results of thermogravimetric analysis showed that GEC electrodes with best electrochemical response to redox probe, and best results in detection of free purine bases in solution and singlestranded DNA, possess $15-26 \%$ of insulating phase (epoxy resin).

These GCE electrodes were successfully applied for the analysis of adenine, mixture of free adenine and guanine in the solution and single-stranded DNA.

The obtained results may serve for the subsequent development of DNA sensors without electrochemical markers.

Acknowledgement: To the Materials Characterization Department, Phase Analysis Laboratory of the Research Center for the Mining and Metallurgical Industry (CIPIMM) for thermogravimetric analysis.

\section{References}

[1] M. I. Pividori, S. Alegret, Comprehensive Analytical Chemistry 49 (2007) 439-466. https://doi.org/10.1016/S0166-526X(06)49021-8

[2] A. I. Balbin Tamayo, L. S. López Rizo, M. Blanco de Armas, H. Yamanaka, A. M. Esteva Guaz International Journal of Biosensors \& Bioelectronics 4(5) (2018) 217-219.

https://doi.org/10.15406/ijbsbe.2018.04.00129

[3] M. S. Ozsoz (ed.), Electrochemical DNA Biosensors, $1^{\text {st }}$ Edition, Jenny Stanford Publ., New York, 2012. https://doi.org/10.1201/b11988

[4] E. Zacco, M. Pividori, X. Llopis, M. del Valle, S. Alegret, Journal of Immunological Methods 286(1-2) (2004) 35-46. https://doi.org/10.1016/j.jim.2003.11.014

[5] D. O'Hare, J. V. Macpherson, A. Willows, Electrochemistry Communications 4(3) (2002) 245250. https://doi.org/10.1016/S1388-2481(02)00265-5

[6] M. Wissler, Journal of Power Sources 156(2) (2006) 142-150. http://dx.doi.org/10.1016/i.jpowsour.2006.02.064

[7] V. N. Kiryushov, L. I. Skvortsova, T. P. Aleksandrova, Journal of Analytical Chemistry 66(5) (2011) 510-514. https://doi.org/10.1134/S1061934811050091 
[8] M. I. Pividori, A. Merkoçi, S. Alegret, Biosensors and Bioelectronics 19(5) (2003) 473-484. https://doi.org/10.1016/S0956-5663(03)00222-7

[9] A. J. C. Aphesteguy, S. E. Jacobo, Avances en Ciencias e Ingeniería 4(3) (2013) 37-48.

[10] C. M. F. Calixto, R. K. Mendes, A. C. de Oliveira, L. A. Ramos, P. Cervini, É. T. G. Cavalheiro, Materials Research 10(2) (2007) 109-114. https://doi.org/10.1590/S151614392007000200003

[11] L. S. López-Rizo, A. I. Balbin-Tamayo, M. Blanco-de-Armas, A. M. Esteva-Guas, Revista Cubana de Hematología, Inmunología y Hemoterapia 33 (2017). http://www.revhematologia.sld.cu/index.php/hih/article/download/785/745

[12] A. I. Balbin Tamayo, Desarrollo de un nuevo electrodo epoxi-grafito para la detección de AND, PhD Thesis, Universidad de La Habana, 2017.

[13] A. I. Balbin Tamayo, L. S. Riso, A. Pérez Gramatges, P. A. Marini Farías, A. M. Esteva Guas, H. Yamanaka, Sensors \& Transducers 202(7) (2016) 59-65. https://www.sensorsportal.com/HTML/DIGEST/july 2016/Vol 202/P 2841.pdf

[14] A. J. Bard, L. R. Faulkner, Electrochemical Methods: Fundamentals and Applications, Second Edition, J. Willey \& Sons Inc., 2001. p. 482. ISBN 0-471-04372-9

[15] Z. Q. Gong, A. N. A. Sujari, S. Ab Ghani, Electrochimica Acta 65 (2012) 257-265. https://doi.org/10.1016/i.electacta.2012.01.057

[16] R. Montes, J. Bartrolí, F. Céspedes, M. Baeza, Journal of Electroanalytical Chemistry 733 (2014) 69-76. https://doi.org/10.1016/i.jelechem.2014.09.022

[17] M. M. Barsan, M. E. Ghica, C. M. A. Brett, Analytica Chimica Acta 881 (2015) 1-23. http://dx.doi.org/10.1016/i.aca.2015.02.059

[18] X. Ba, L. Luo, Y. Ding, Z. Zhang, Y. Chu, B. Wang, X. Ouyang, Analytica Chimica Acta 752 (2012) 94-100. https://doi.org/10.1016/i.aca.2012.09.031

[19] A. X. H. Yong, G. D. Sims, S. J. P. Gnaniah, S. L. Ogin, P. A. Smith, Advanced Manufacturing: Polymer \& Composites Science 3(2) (2017) 43-51. https://doi.org/10.1080/20550340.2017.1315908

[20] A. C. O. Santana, E. F. Southgate, J. P. B. G. Mendes, J. Dweck, E. M. Alhadeff, N. I. B. Ramirez, Journal of Electrochemical Science and Engineering 4(4) (2014) 165-175. https://doi.org/10.5599/jese.2014.0057.

[21] A. L. M. Azevedo, P.S. de Oliviera, E. A. Ponzio, F. S. Semaan, IOP Conference Series: Materials Science and Engineering 97(1) (2015) 012008. https://doi.org/10.1088/1757$\underline{899 X / 97 / 1 / 012008}$

[22] A. I. Balbin-Tamayo, L. S. Riso, A. M. Esteva Guas, P. A. Mardini-Farias, A. Pérez-Gramtages, Revista Cubana de Química 29(1) (2017) 115-132. https://cubanaquimica.uo.edu.cu/index.php/cq/article/view/1996/1989

[23] OligoEvaluator. http://www.oligoevaluator.com/OligoCalcServlet (Accessed January 2021)

[24] R. G. Compton, C. E. Banks, Understanding Voltammetry, Third edition, World Scientific, 2018. ISBN 17-8634-529-3

[25] J. M. Pingarrón Carrazón, P. Sánchez Batenero, Química Electroanalítica: Fundamentos y Aplicaciones, Síntesis, Madrid, 1999. ISBN 84-7738-663-3

[26] P. Zanello, Inorganic Electrochemistry: Theory, Practice and Application, Royal Society of Chemistry, 2003. https://doi.org/10.1039/9781847551146

[27] S. H. Goodman (ed.), Handbook of Thermoset Plastics, Noyes Publications, 1998. ISBN 159124-094-8

[28] J. Wang, Analytical Electrochemistry, Second Edition, Wiley-VCH, 2001. ISBN 0471-28272-3

[29] R. S. Nicholson, Analytical Chemistry 37(11) (1965) 1351-1355. https://doi.org/10.1021/ac60230a016 
[30] A. Oliveira-Brett, J. A. P. Piedade, L. A. Silva, V. C. Diculescu, Analytical Biochemistry 332(2) (2004) 321-329. https://doi.org/10.1016/i.ab.2004.06.021

[31] E. Palecek, F. Scheller, J. Wang (eds.), Electrochemistry of nucleic acids and proteins: towards electrochemical sensors for genomics and proteomics, Elsevier, 2005.

[32] H. Yin, Y. Zhou, Q. Ma, S. Ai, P. Ju, L. Zhu, L. Lu, Process Biochemistry 45(10) (2010) 17071712. https://doi.org/10.1016/i.procbio.2010.07.004

[33] P S. Pruneanu, A. R. Biris, F. Pogacean, M. Coroş, G. K. Kannarpady, F. Watanabe, A. S. Biris, Electrochimica Acta 139 (2014) 386-393. https://doi.org/10.1016/j.electacta.2014.06.163

[34] M. Arvand, M. Sanayeei, S. Hemmati, Biosensors and Bioelectronics 102 (2018) 70-79. https://doi.org/10.1016/i.bios.2017.11.002

[35] M. Arvand, R. Mothaged Mazhabi, A. Niazi, Electrochimica Acta 89 (2013) 669-679. https://doi.org/10.1016/j.electacta.2012.11.014

[36] B. Atiqa, A. Elharf, Moroccan Journal of Chemistry 4(1) (2016) 61-67. https://doi.org/10.48317/IMIST.PRSM/morjchem-v4i1.3696

[37] R. Hsissou, Y. El Rhayam, A. Elharfi, International Journal of Innovation and Applied Studies 7(2) (2014) 674-682. http://www.ijias.issr-journals.org/authid.php?id=1672 